This document is the author's version of an accepted manuscript of a published work that appeared in final form in Quality in Ageing and Older Adults, copyright (c) Emerald Publishing after peer review and technical editing by the publisher. To access the final edited and published work see [https://doi.org/10.1108/QAOA-04-2018-0016].

\title{
How formal navigators interpret their roles supporting families
}

Laura M. Funk, PhD

Associate Professor, Department of Sociology and Criminology, University of Manitoba. 307-

183 Dafoe Road, Isbister Building, Winnipeg, Manitoba, Canada R3T2N2. Phone: 204-474-6678

Fax: 204-261-1216 Email: Laura.Funk@umanitoba.ca

Wanda Hounslow, BA

Research Assistant, Department of Sociology, University of Manitoba, 183 Dafoe Road, Isbister Building, Winnipeg, Manitoba, Canada R3T2N2. Phone: 204-474-6678 Fax: 204-261-1216

Email: hounslow@myumanitoba.ca

\section{Acknowledgements}

We appreciate the funding of Research Manitoba for this study, as well as the time and insights provided by all participants. We gratefully acknowledge the assistance of the Winnipeg Regional Health Authority in helping with recruitment, as well as the help of Ms. Erin Scott (interviewing) and Ms. Catherine Davey (transcription). 
This document is the author's version of an accepted manuscript of a published work that appeared in final form in Quality in Ageing and Older Adults, copyright (c) Emerald Publishing after peer review and technical editing by the publisher. To access the final edited and published work see [https://doi.org/10.1108/QAOA-04-2018-0016].

\title{
How formal navigators interpret their roles supporting families
}

\begin{abstract}
Purpose - This study examined how formal navigators interpret their roles supporting families of older adults.
\end{abstract}

Design/methodology/approach - This study was an interpretive inquiry informed by critical gerontology and discourse analytic methods. Interview data were collected and analyzed from 22 formal service providers who helped older adults and their families navigate health and social care resources in one Western Canadian city.

Findings - Although acknowledging structural barriers to service access, participants emphasized individual empowerment as their dominant strategy, interpreting their roles as providing information and education about services. In part, these interpretations may reflect the limited nature of their ability to help broker access or advocate; in part, they may also reflect the broader political and economic discourses surrounding care in Canada.

Limitations: When providers position navigation and access to care as individual problems, this can obscure structural burden as well as potential inequities among older adults. Future research should examine whether navigational role interpretations are similar or different to those of navigators in other regions. Navigators in other health and social care contexts may enact differing meanings in their work. 
This document is the author's version of an accepted manuscript of a published work that appeared in final form in Quality in Ageing and Older Adults, copyright (c) Emerald Publishing after peer review and technical editing by the publisher. To access the final edited and published work see [https://doi.org/10.1108/QAOA-04-2018-0016].

Practical implications - Although formal public navigators can play an important role, approaches that go beyond providing information may better meet families' needs for support.

Originality/Value - This is one of the first studies focused specifically on providers' interpretations of the meaning of navigational work in health and social care for older adults, and to extend a critical gerontological gaze towards the issue of system navigation.

Keywords: system navigation; family caregiving; access to care; structural burden; interpretive inquiry; critical gerontology 
This document is the author's version of an accepted manuscript of a published work that appeared in final form in Quality in Ageing and Older Adults, copyright (c) Emerald Publishing after peer review and technical editing by the publisher. To access the final edited and published work see [https://doi.org/10.1108/QAOA-04-2018-0016].

\section{Introduction}

The care needs and issues faced by older adults and their families vary greatly, frequently blur the boundary between health and social needs, and often include multiple chronic conditions as well as transitions between service settings reflecting changes over time. These needs are compounded by health and social care systems that, although considerably diverse and complex, are also fragmented and uncoordinated, thus difficult for older adults and their families to navigate. For instance, typically home care and nursing home settings are organized and delivered in different ways, generating confusion for older adults and families during transition.

Navigational work is especially salient in the context of formal services that are fragmented, as well as, in more recent years, more difficult to access (Bookman and Harrington, 2007; Koehn, 2009). Although publicly-funded, non-medical care resources have never been universally guaranteed in Canada, policy shifts since the 1980s have eroded access to both medically necessary services as well as formal social and preventive supports, such as home care (Segall and Chappell, 2000). Accompanied by the diffusion of market-based, individualizing ideologies across sectors involved in caring for older adults, such shifts are also aimed at moving care delivery for older adults out of institutions into home and community, where families take up increasing proportions of costs and responsibilities (Aronson, 2006; Chappell, 1993; Williams et al., 2001).

These shifts provide important context in which to understand the work that older adults and their families do to access and coordinate various services and resources. There is emerging concern in this regard about how the work required to navigate services can contribute to carer 
This document is the author's version of an accepted manuscript of a published work that appeared in final form in Quality in Ageing and Older Adults, copyright (c) Emerald Publishing after peer review and technical editing by the publisher. To access the final edited and published work see [https://doi.org/10.1108/QAOA-04-2018-0016].

burden (authors, in press; Taylor and Quesnel-Vallée, 2017) as well as hinder access, generating inequities among older adults (Dixon Woods et al., 2006). Existing research documents challenges faced by ethnocultural minority and low income older adults and their families in navigating and accessing care services (e.g., Koehn et al., 2009); these challenges, such as language and literacy, are mediated by the context in which services are delivered (Rootman and Gordon El-Bihbety, 2008).

A need has emerged for health and social care providers to provide navigational support to older adults and their families, and professionalized, formal navigator positions are being developed in North America, designed as system innovations to reduce barriers to accessing care and promote care equity (Dohan and Schrag, 2005, Manderson et al., 2012). Primarily these positions are targeted to specific disease categories (predominantly cancer), with a focus on navigating medical care and sometimes accessing other formal services. More recently in Canada, these positions have been implemented in other sectors such as home care and long-term care for older adults, with a focus on ensuring smooth transitions between settings and improving consumer access to information about resources and services. Private consultants have also been entering the field to perform this work for well-resourced families, and non-profit agencies across several sectors continue to play an important role.

Extant literature generally defines patient navigators as providing information, brokering access to health services, and alleviating barriers in marginalized populations (Egan et al., 2010; Health Council of Canada, 2013; Manderson et al., 2012). Emerging evidence suggests these positions can be beneficial (Bradford et al., 2007; Colombo et al., 2011; Corrigan et al., 2014; 
This document is the author's version of an accepted manuscript of a published work that appeared in final form in Quality in Ageing and Older Adults, copyright (c) Emerald Publishing after peer review and technical editing by the publisher. To access the final edited and published work see [https://doi.org/10.1108/QAOA-04-2018-0016].

Manderson et al., 2012; Robinson-White et al., 2010). As navigator initiatives have expanded beyond cancer care, however, this appears to have been accompanied by increasing lack of consensus about the scope of navigator roles (e.g., whether it includes advocacy and other forms of support). Moreover, less is known about how formal navigators in other sectors help older adults and their families access non-medical, social resources and supports.

It is imperative to understand how health and social care professionals interpret the meaning of system navigation, as these interpretations inform the work they do with older adults and their families. To date, there has been little in-depth and detailed investigation into how formal navigators understand the meaning and purpose of their work and role. This is important, since there may be increasing emphasis on navigational supports in the future, and navigators' role interpretations can inform their practice; moreover, from a critical gerontological perspective, these role interpretations can provide insights into broader circulating discourses about care responsibility. The purpose of this study was to explore role interpretations in a diverse range of service providers who assist older adults and their families with accessing services and supports (i.e., formal service navigators).

\section{Methods}

In keeping with a focus on meanings constructed in social interaction (in this case, the research interview), qualitative, interpretive inquiry (Gubrium and Holstein, 2000) informed by critical gerontology (Grenier, 2012) guided study design. Interpretive inquiry draws on social phenomenology and discourse analytic traditions to examine how individuals make sense of everyday practices by drawing on broader socio-cultural frameworks of meaning (Atkinson et 
This document is the author's version of an accepted manuscript of a published work that appeared in final form in Quality in Ageing and Older Adults, copyright (c) Emerald Publishing after peer review and technical editing by the publisher. To access the final edited and published work see [https://doi.org/10.1108/QAOA-04-2018-0016].

al., 2003). With formal system navigation, these frameworks of meaning could include, for example, organizational discourses prevalent in health and social care fields. A critical gerontological approach (Grenier, 2012) promotes empirically informed critical analyses and interpretations that in this study involved considering the broader sources and potential implications of particular social and cultural constructions of system navigation that emerged in the interviews.

Following institutional REB approval (from the university and regional health agency), three general types of formal service navigators from one large Western Canadian city were recruited to participate in in-person, semi-structured qualitative interviews (April - August 2016). This included regional public employees (e.g., long term care navigators, clinical social workers, home care case coordinators and community resource coordinators), referred to herein as 'public navigators'; employees of local non-profit organizations serving older adults and/or carers (e.g., executive directors, client support coordinators); and private consultants. Our operational definition of navigators was broad, so as to recruit a range of navigators, including traditional 'patient' navigators as well as professionals helping older adults access social care resources. Participants were recruited through invitation letters distributed by managers and supervisors of various public agency and non-profit departments and organizations, and cold calls to private consultants identified through internet searches. Managers and supervisors were asked to forward the letter to employees in positions involving a substantial focus on system navigation with older adults and their families. Potential participants contacted the first author directly. 
This document is the author's version of an accepted manuscript of a published work that appeared in final form in Quality in Ageing and Older Adults, copyright (c) Emerald Publishing after peer review and technical editing by the publisher. To access the final edited and published work see [https://doi.org/10.1108/QAOA-04-2018-0016].

Qualitative interviews with 22 participants, preceded by a written informed consent process, were guided by broad questions about participants' role and position, the work they did helping families navigate systems for or with older adults, common navigational barriers they believed families encountered, and whether particular groups of families were disadvantaged in navigating. Generally, participants chose to be interviewed either in a research office or other private, quiet locations close to but not directly within their usual workspaces (a few opted for their homes). All interviews except two were with just one individual; in three interviews, multiple participants (2 and 3) from the same organization participated. The second author was one of the interviewers; the other interviewer was a research assistant.

Interviews (averaging roughly an hour in length) were audio-recorded, transcribed and analyzed by the first and second authors using discourse analytic techniques (Cheek, 2004; Powers, 1996; Smith, 2007). The data contained participant descriptions of how they interpreted their roles and defined system navigation; perceived barriers to, and sources of disadvantage for families who are trying to navigate systems; and perspectives about improving families' system navigation experiences. After close reading of interview transcripts and listening to audio, we examined these data and through iterative discussion and collaboration, and developing and reviewing visual tables, we identified, coded, and then further explored and refined our understanding of common discursive themes, including those that threaded across these descriptive topics. We examined and discussed comparisons and contradictions in meanings expressed within and across interviews and sought to identify variation. Identified themes reflected explicit and implicit meanings we identified in participants' talk about system 
This document is the author's version of an accepted manuscript of a published work that appeared in final form in Quality in Ageing and Older Adults, copyright (c) Emerald Publishing after peer review and technical editing by the publisher. To access the final edited and published work see [https://doi.org/10.1108/QAOA-04-2018-0016].

navigation work. Our analysis also reflected a critical perspective in which our analysis of the stated meanings (as well as what was 'not' said) was informed by our knowledge of the broader context of health and social care service delivery for older adults in Canada. We had no significant analytic disagreements during this evolving process, in which we continually refined our understanding of the data. Rigorous, worthy and credible analysis was promoted through attention to complex contextualized meanings in the data, thereby moving beyond describing, to unfolding abundant, relevant and concrete detail (i.e., thick description, as per Tracy, 2010).

\section{Findings}

\section{Interpreting the core problem of navigation: families' lack of information, skills, and the}

right dispositions. Provider role interpretations draw on and reinforce particular interpretations of the problem of formal navigational work. Throughout their interviews, all three types of participants spoke about several closely related individual-level barriers faced by families navigating formal systems: a lack of accurate knowledge (e.g., about available resources and how to access these, what questions to ask, system literacy, being an 'educated consumer'), skills (e.g., interpersonal, making needs visible to providers), and personal dispositions (e.g., being persistent, not afraid to advocate, comfortable asking for help, prepared, having reasonable expectations).

Conversely, with the right information (and some encouragement), access was generally believed to be easier. Here, navigators position their role in supporting families; in other words, participants' role characterizations aligned with this dominant definition of the problem. Participants similarly tended to position their roles as empowering families through educating 
This document is the author's version of an accepted manuscript of a published work that appeared in final form in Quality in Ageing and Older Adults, copyright (c) Emerald Publishing after peer review and technical editing by the publisher. To access the final edited and published work see [https://doi.org/10.1108/QAOA-04-2018-0016].

and providing information about how to access services and resources (publicly funded, in some cases private or non-profit) and interact with formal providers. For instance, one private consultant characterized her work as "[giving] people an opportunity to be empowered and how to look after themselves and get care for themselves." A representative from a non-profit organization further stated that they hope "we have empowered [familie] to know where to go to get the information that they need and then as a backup plan they can always call us."

To a lesser extent, insufficient community services and resources were identified as creating challenges for families trying to access help for an older adult. This generated feelings of powerlessness or moral distress in some participants. As an example, one participant referred to the shortage of nursing home beds:

Families will bargain with, barter with me. They'll plead with me. They'll threaten me because they want so badly for their loved one to go [to the nursing home] they want to go to. But I always say, I can't create a bed where there is not one... It's out of my control. I don't have the resources to give everybody what they want all the time. (public navigator)

An alternative interpretation was expressed by three public navigators who framed the problem as rooted in families' high expectations of systems (e.g., lack of awareness and acceptance of constraints). For instance, one public navigator characterized the public as having a sense of 
This document is the author's version of an accepted manuscript of a published work that appeared in final form in Quality in Ageing and Older Adults, copyright (c) Emerald Publishing after peer review and technical editing by the publisher. To access the final edited and published work see [https://doi.org/10.1108/QAOA-04-2018-0016].

entitlement and expectation for services and in some cases not appreciating what is available; in these cases, she interpreted her role as providing a 'clarification' or a 'tune-up' to address this disjuncture. Another public navigator likewise communicates to families: "this is what we have to offer. It's great that we have it at all, so be thankful."

\section{Interpreting navigation as guidance or coaching towards particular options. As an}

exception to the dominant emphasis on information, in some cases, providers characterized their role as assessing the needs of the older adult and providing targeted recommendations or suggestions reflecting that assessment. In particular, public navigators employed by the health agency spoke about "hooking people up to the appropriate resources," "getting them to the right direction," providing information in a way so as to "match needs with services," or "figure out what makes a good fit." Moreover, at times navigational guidance was characterized as supporting organizational goals, such as quick and seamless flow through systems, avoiding or shortening hospital stays, and even mobilizing family responsibility. For instance, one public navigator explained how, after talking about the limits of formal services with families, she prompts them to consider more personal involvement: "opening up the conversation to say "what can we do for you to help you help your mom or dad."' Other participants spoke about how their work alleviated the burden of calls to family doctors from anxious and confused families, and one consultant described when she tells families not to bother the health care team with unnecessary questions: "I call them off the team in that way."

Participants tended to posit their specialized knowledge as making them well suited to guide older adults and their caregivers through complex systems, as in: "we're the ones that have 
This document is the author's version of an accepted manuscript of a published work that appeared in final form in Quality in Ageing and Older Adults, copyright (c) Emerald Publishing after peer review and technical editing by the publisher. To access the final edited and published work see [https://doi.org/10.1108/QAOA-04-2018-0016].

the knowhow and can't possibly expect them to know the intricacies of all these problems" (public navigator). One non-profit representative further suggested that "being outside the health system helps us to objectively give information." She believed that some health care system gatekeepers may be more inclined than others to withhold certain information about the available scope and depth of services "because of pressure to make the best use of health resources." In contrast, as an independent organization, for instance:

...what we can do is say really you can have up to 55 hours [of home care] if you're an employed person caring for someone. Be aware that even if they only say you can have 10 or 15 hours of assistance that the parameters are such that you can go to this level...we can have very factually just put it on the table and say it's there - feel good about asking.

Interpreting navigation as involving advocacy and direct support. Participants varied widely in the extent to which they believed they could initiate or activate resources for families. There was less evidence in the interviews of role interpretations reflecting active involvement in coordinative or administrative work involved in accessing services, or advocacy, with a few exceptions that may in part reflect participants' differing formal positions. Private consultants, for instance, tended to express more involvement in helping to coordinate care between multiple services. Other navigators spoke of becoming involved in communicating with professionals on behalf of families, or other forms of advocacy in "exceptional" cases. 
This document is the author's version of an accepted manuscript of a published work that appeared in final form in Quality in Ageing and Older Adults, copyright (c) Emerald Publishing after peer review and technical editing by the publisher. To access the final edited and published work see [https://doi.org/10.1108/QAOA-04-2018-0016].

As examples, one public navigator spoke about how she tried to convince a home care nurse to conduct an assessment that was needed to obtain a specialized therapeutic mattress: "I had to do a lot of advocating in this particular situation, for the client's best interest I nag, and harp, and email a few different people." Another public navigator spoke of how she tries, where possible, to help older adults access their preferred choice of nursing home, adding:

Sometimes the client may have a little bit of a quirk or whatever ... and I'll phone the [nursing home] and say 'You're going to get an application soon'... and they'll often say 'we already got it but this person doesn't look to be maybe a good fit.' So I'll advocate on the client's behalf and offer to come down and meet with the [nursing home] to discuss it a little bit more.

A private consultant also referred to encouraging health care providers to provide flexible or creative solutions to meet client needs, describing this as "pushing" the system to be more flexible and less "patronizing to some of the families about knowing what's best, when they don't know necessarily what it means to this family or individual."

As the needs of older adults can sometimes conflict with those of their families, participants also spoke of examples in which they intervened on behalf of carers to convince older adults to accept home-based formal services; they also provided examples in which they convinced family carers to help keep older adults at home who do not wish to move into a nursing home (or convince them to let this transition happen, if this is their wish). 
This document is the author's version of an accepted manuscript of a published work that appeared in final form in Quality in Ageing and Older Adults, copyright (c) Emerald Publishing after peer review and technical editing by the publisher. To access the final edited and published work see [https://doi.org/10.1108/QAOA-04-2018-0016].

The representative of a non-profit agency described herself as particularly well positioned to help families with advocacy, referring indirectly to the power of her status and social capital, derived from years of experience in the field. She believed this helped alert health care providers to particular client issues and needs: "They pay attention when I call. But I always think it's a shame when they didn't pay attention when 'Mr. Smith' called because he called them too and they didn't do anything."

In telling these stories about their work, some participants conveyed role interpretations that included these more active forms of navigational support. However, more commonly participants described less direct approaches such as equipping families with self-advocacy tips, telling them what questions to ask or how to advocate to have their concerns and needs for services addressed. This can include prompting them to ask for specific services they may not have known were available. Other participants encouraged families "not to be afraid" to advocate, or showed them how to write a letter of complaint.

Several participants expressed that they wanted to do more to help more families navigate systems, including advocacy (i.e., it was part of their role interpretation), but believed they did not have enough time to do this in the way they would like (due to resource limitations). One non-profit representative explained how this meant: "we have to be very careful and diligent on picking and choosing who we're really going to 'go to war' for because we can't possibly do it for everybody." As another example, a public navigator noted: 
This document is the author's version of an accepted manuscript of a published work that appeared in final form in Quality in Ageing and Older Adults, copyright (c) Emerald Publishing after peer review and technical editing by the publisher. To access the final edited and published work see [https://doi.org/10.1108/QAOA-04-2018-0016].

Big caseloads do not allow us the time to help people as much as we would like to. We don't want to do everything for people but you want to be able to support them and give them the tools and help advocate when it's appropriate and navigate.

Interpreting structural barriers as individual deficits. As noted above, carers' lack of knowledge about available services (and how to access them) was an almost ubiquitous thread throughout interviews, in many ways positioned as the raison d'être for formal navigational support. In most cases, to elicit conversation on other types of barriers faced by families, the interviewer had to ask a targeted, specific question.

Moreover, participants rarely if ever spoke unprompted about disadvantaged groups of carers and families who face barriers to accessing formal services. Further, none defined their role as directly addressing the issue of inequities in service access for older adults. A few participants, drawing on frameworks that position the problem as rooted in individual qualities (e.g., lack of knowledge; emotional responses) denied the existence of group inequities directly, as in the following example:

I think you see struggles right across the board. I wouldn't want to pinpoint and say that these families seem to struggle more. The lack of knowledge, that happens wherever or whoever you talk to. (public navigator) 
This document is the author's version of an accepted manuscript of a published work that appeared in final form in Quality in Ageing and Older Adults, copyright (c) Emerald Publishing after peer review and technical editing by the publisher. To access the final edited and published work see [https://doi.org/10.1108/QAOA-04-2018-0016].

Overall, structural barriers tended to be framed as individual problems or deficits, even if related in some cases to culture or language, or to poverty or access to transportation. For instance, although population groups of immigrant or newcomer families, including those who struggle with English language, were mentioned by participants as facing more barriers, these barriers tended to be framed as a group-specific problem of lack of awareness, communication or comprehension of English language, or cultural norms of family responsibility that can make it difficult for some family members to reveal their needs to formal providers. In a few cases, broader structural roots of these problems were alluded to, as with one non-profit representative who described the delays involved in accessing an interpreter through the public health authority for families that struggle with English language.

Barriers to access related to poverty and educational level, acknowledged by many participants, also tended to be framed as individual deficits. Participants described persons with lower education and socio-economic status as less knowledgeable about services, less skilful in speaking to professionals about service issues or concerns, less resourceful, and more passive or fearful in interactions with professionals. Again, structural frameworks were sometimes invoked, as when one public navigator explained the complex reasons why some patients miss their medical appointments:

[They] got an opportunity to go look at an apartment on that day. Or [they] got a call from [Housing agency] and there was something available and [they] had to go meet with them 
This document is the author's version of an accepted manuscript of a published work that appeared in final form in Quality in Ageing and Older Adults, copyright (c) Emerald Publishing after peer review and technical editing by the publisher. To access the final edited and published work see [https://doi.org/10.1108/QAOA-04-2018-0016].

right there and then... And unfortunately the medical system right is not always very forgiving...If you don't show up twice, sometimes that's it...

She added that although these patients recognize the importance of their medical appointments, they "ultimately also have to have a place to stay."

Moreover, some participants expressed that carers may not have the means to provide transportation or hire private transportation when publicly subsidized services, such as HandiTransit, are unavailable to due long waitlists or service restrictions.

Notably, one public navigator invoked the rhetoric of individual responsibility in part to mitigate potential feelings of guilt when she could not address the complex structural socioeconomic and social factors limiting one particular client's access to care. She described one of her low-income clients who lived alone with addiction and without community supports, transportation or a phone. His medical needs were substantial, yet he was not eligible for home care. She did her best to get him a phone, ensure he got to an appointment, and notify his daughter who lived out of town: “and he goes 'Who's gonna check up on me now? What happens if I can't get out of bed? What happens if I die?' I didn't have an answer for that... What am I supposed to do?" She expressed relief in knowing now that he eventually got into an apartment and had access to post-surgical nursing care, but added: 
This document is the author's version of an accepted manuscript of a published work that appeared in final form in Quality in Ageing and Older Adults, copyright (c) Emerald Publishing after peer review and technical editing by the publisher. To access the final edited and published work see [https://doi.org/10.1108/QAOA-04-2018-0016].

There's lots of things that I can't solve and ... personally there's some choice, I have to remember. There's some choice that he had to make to get there. There's also family responsibility that I have to remember and then there's system because I can't solve all his problems.

Interpreting navigation as a systemic, structural problem. To a much lesser extent, and most often in response to targeted questions from the interviewer, some participants characterized system fragmentation as a barrier and the root of the problem of system navigation. This included the existence of silos lacking in lateral communication, a lack of centralization and standardization or continuity of procedures, and system inflexibility to complex, individualized needs. Two excerpts are illustrative:

Hospital [providers] tell you about nursing home placement from their perspective. Meaning...we don't have time to talk about criteria for selection. Community [providers] say we don't know a lot about the nursing homes anymore because we're too far removed from that. So we can't help you but here's the list. (private consultant)

[Systems] can be quite fragmented, they all have different criteria, and often we've designed the systems such that.. you can't pass go until you've spoken to [someone in an 
This document is the author's version of an accepted manuscript of a published work that appeared in final form in Quality in Ageing and Older Adults, copyright (c) Emerald Publishing after peer review and technical editing by the publisher. To access the final edited and published work see [https://doi.org/10.1108/QAOA-04-2018-0016].

authority role], we've made them with these checks and balances which turn out to be a little less user friendly. So I think that's a reason why we need navigators (laughs) is we've just made it so that it tends to be that you need to speak to a few people in order to get things in place. (public navigator)

Some participants believed that systemic or structural features of health and social care systems (e.g., multiple assessments and workups, multiple points of entry, lack of centralized information hub) generated and complicated navigational work by families, who were also often simultaneously going through difficult emotional times in their lives. Adding to this complexity, a few participants suggested older adults' needs and circumstances were becoming more diverse and complex, and that caregiving and health trajectories were quite complex, variable, and unpredictable.

Moreover, in a silo-based system, as one public navigator stated, such complexity makes it more difficult for providers to deal with older adults' needs effectively, resulting in the client being "shuffled" between multiple organizations or agencies (complicating navigation). System complexity, a lack of clear information (about patients and/or services) and system fragmentation were also described as limiting participant's abilities to provide effective navigational support in other ways. As one public navigator stated: “I'm IN the system and I'm confused about what I'm supposed to be doing ... so I can see how it can be SO confusing for people who aren't in the system." 
This document is the author's version of an accepted manuscript of a published work that appeared in final form in Quality in Ageing and Older Adults, copyright (c) Emerald Publishing after peer review and technical editing by the publisher. To access the final edited and published work see [https://doi.org/10.1108/QAOA-04-2018-0016].

\section{Discussion and Conclusions}

Future research should examine how these navigational role interpretations compare to navigators in other geographic regions and health and social care contexts (including settings outside of Canada), since formal navigators in these contexts may understand and approach their work differently. Another limitation of this study is the focus only on language, rather than practice. Observational and case study approaches should ascertain whether providers' stated role interpretations align with or contradict their everyday approaches to working with families. Moreover, it should not be assumed that these findings reflect the experiences of older people themselves, or their families. Future research needs to examine how older adults and their families experience their interactions with formal navigators, including their satisfaction with various kinds of navigational supports.

Nonetheless, in relation to existing literature and approaches to the study of system navigation, this research is novel in its focus on providers' interpretations of the meaning of navigational work in both health and social care for older adults, as well as in the application of a critical gerontological perspective. A unique finding of this research was that the main problem of navigation tended to be framed as an individual-level problem of insufficient knowledge and skills among families. From this perspective, the dominant navigational support role was framed as individual empowerment and educating older adults and their families about how to access services. The far lesser emphasis on more substantial, direct forms of navigational support (including advocacy) may partly reflect limitations in participants' job descriptions, and time and workload constraints. In this way, material conditions shape role definitions; these in turn 
This document is the author's version of an accepted manuscript of a published work that appeared in final form in Quality in Ageing and Older Adults, copyright (c) Emerald Publishing after peer review and technical editing by the publisher. To access the final edited and published work see [https://doi.org/10.1108/QAOA-04-2018-0016].

reinforce broader circulating meanings of system navigation and access to care. Moreover, formal navigators did not inductively or reflexively question how systems place the onus on families to do navigational work to access services, and none directly interpreted their roles as helping to alleviate inequities among older adults in access to services. Instead, they tended to frame their roles more broadly as supporting older adults and their families, and in some cases, on alleviating pressures on formal health care services. Such patterns may be understood in relation to the broader social context in which families and patient consumers are increasingly responsibilized by professionals, equipped with the skills necessary to self-navigate complex systems on their own. Service providers themselves, who are strongly committed to helping families navigate systems, can inadvertently recycle this system interpretation of the problem as a private trouble of individuals, particularly in situations where they are themselves constrained to help effectively. Neoliberal patterns of talk have also been documented among home care nurses (Ceci and Purkis, 2009; Funk et al., 2011) and social service providers (Woolford and Curran, 2012).

Public and private navigators in this study appeared to focus on navigational support during key transition or crisis periods (e.g., after diagnosis, when there was significant change in health status), or when asked directly by families. There may also be a benefit of informing families about services "proactively and prior to crises" (MacCourt and Krawczyk, 2012: p.27), although time and workload constraints may hamper this approach. Likewise, it could be argued that formal navigators also need the time (and power) to become engaged in a way that can help reduce inequities between older adults in accessing formal services. Although private consultants can offer tailored and immediate in-depth advocacy and navigational supports to those with the 
This document is the author's version of an accepted manuscript of a published work that appeared in final form in Quality in Ageing and Older Adults, copyright (c) Emerald Publishing after peer review and technical editing by the publisher. To access the final edited and published work see [https://doi.org/10.1108/QAOA-04-2018-0016].

ability to pay, this may exacerbate the potential inequities that navigational supports were originally intended to address.

This research also raises other issues that remain to be discussed further by those developing system navigation supports. For instance, navigational support positions operationalized within care systems may be better poised (e.g., than non-profit employees) to take action to help families overcome access barriers, depending on their authority, internal knowledge and system connections. However, there is also a risk, when relying on system staff as navigators, that broader equity goals may become subordinated to organizational goals of reducing reliance on formal services (e.g., quick hospital discharge). For some public navigators in the present study, who had considerably more control in brokering families' access to formal services, navigation was closer to gatekeeping, and initiating service access (after needs assessment) may have been a more fundamental part of their role. However, prioritizing the input and perspective of older adults and their families is key to successful formal navigational support precisely because older adults needs' are not always discrete or clearly discernable to those working within fragmented systems.

Public and non-profit navigational positions are an important step in rectifying problems with flows of service information to older adults and may help alleviate structural burden on carers (Author ref). However, these approaches alone may be insufficient, in light of some participant comments regarding the roots of the problem in system fragmentation. Integrated care approaches may be best able to address problems with navigation and access to care, and we need to be careful to avoid developing a reliance on system navigator positions, at the expense of 
This document is the author's version of an accepted manuscript of a published work that appeared in final form in Quality in Ageing and Older Adults, copyright (c) Emerald Publishing after peer review and technical editing by the publisher. To access the final edited and published work see [https://doi.org/10.1108/QAOA-04-2018-0016].

thinking more 'upstream.' We cannot, in other words, avoid 'the bigger and more involved issue of integration" of the broad range of services and supports for older adults (Manderson et al. 2012, p.114).

\section{References}

Aronson, J. (2006). "Silenced complaints, suppressed expectations: The cumulative effects of home care rationing”, International Journal of Health Services, Vol. 36 No. 3, pp. 53556.

Atkinson, A., Coffey, P. and Delamont, S. (2003), Key themes in qualitative research: Continuities and changes, Altamira, Walnut Creek, CA.

Bookman, A. and Harrington, M. (2007), "Family caregivers: a shadow workforce in the geriatric health care system?", Journal of Health Politics, Policy and Law, Vol. 32 No. 6, pp.1005-41.

Bradford, J.B., Coleman, S. and Cunningham, W. (2007), "HIV system navigation: An emerging model to improve HIV care access. AIDS Patient Care and STDs”, Vol. 21 Supplement 1,pp. S49-58. 
This document is the author's version of an accepted manuscript of a published work that appeared in final form in Quality in Ageing and Older Adults, copyright (c) Emerald Publishing after peer review and technical editing by the publisher. To access the final edited and published work see [https://doi.org/10.1108/QAOA-04-2018-0016].

Ceci, C. and Purkis, M.E. (2009), "Bridging gaps in risk discourse: home care case management and client choices", Sociology of Health and Illness, Vol. 31 No. 2, pp. 201-14.

Chappell, N.L. (1993). "Implications of shifting health care policy for caregiving in Canada”, Journal of Aging and Social Policy, Vol 5 No. 1-2, pp. 39-55.

Cheek, J. (2004), “At the margins? Discourse analysis and qualitative research", Qualitative Health Research, Vol 14, pp. 1140-50.

Colombo, F., Nozal-Llena, A., Mercier, J. and Tjadens, F. (2011), Help wanted? Providing and paying for long-term care. OECD Publishing, Paris, France. Available at: http://www.oecd.org/els/health-systems/helpwantedprovidingandpayingforlong-termcare.htm (Accessed April 19 2018).

Corrigan, P.W., Pickett, S., Batia, K. and Michaels, P.J. (2014), "Peer navigators and integrated care to address ethnic health disparities of people with serious mental illness", Social Work in Public Health, Vol 29 No. 6, pp. 581-93.

Dixon-Woods, M., Kirk, M. D., Agarwal, M. S., Annandale, E., Arthur, T., Harvey, J.,_Hsu, R., Katbamna, S., Olsen, R. and Smith, L. (2005), Vulnerable Groups and Access to_Health Care: A Critical Interpretive Review. National Co-ordinating Centre for NHS Service_Delivery and Organisation, London, UK. Available at: http://www.menshealthforum.org.uk/uploaded_files/SDOvulnerablegroups2005.pdf (Accessed February 20 2008).

Dohan, D. and Schrag, D. (2005), "Using navigators to improve care of underserved patients: current practices and approaches”, Cancer, Vol. 104 No. 4, pp. 848-55. 
This document is the author's version of an accepted manuscript of a published work that appeared in final form in Quality in Ageing and Older Adults, copyright (c) Emerald Publishing after peer review and technical editing by the publisher. To access the final edited and published work see [https://doi.org/10.1108/QAOA-04-2018-0016].

Duggleby, W., Robinson, C.A., Kaasalainen, S., Pesut, B., Nekolaichuk, C., MacLeod, R., et al. (2016), "Developing navigation competencies to care for older rural adults with advanced illness", Canadian Journal on Aging, Vol. 35 No. 2, pp. 206-14.

Egan, M., Anderson, S. and McTaggart, J. (2010). "Community navigation for stroke survivors and their care partners: description and evaluation," Topics in Stroke Rehabilitation, Vol. 17 No. 3, pp. 183-90.

Farran, C.J., Loukissa, D., Perraud, S. and Paun, O. (2004), “Alzheimer's disease caregiving information and skills. Part II: Family caregiver issues and concerns", Research in Nursing and Health, Vol. 27 No.1, pp. 40-51.

Funk, L.M., Stajduhar, K.I. and Purkis, M.E. (2011), “An exploration of empowerment discourse within home-care nurses' accounts of practice”, Nursing Inquiry, Vol. 18 No.1, pp. 66-76.

Funk, L.M., Stajduhar, K.I. and Outcalt, L. (2015), "What family caregivers learn when providing care at the end of life: a qualitative secondary analysis of multiple datasets", Palliative and Supportive Care, Vol. 13 No. 3, pp. 425-33.

Grenier, A. (2012). Transitions and the Life Course: challenging the constructions of 'growing old', Policy Press, Bristol, UK.

Gubrium, J. F. and Holstein, J.A. (2000), “Analyzing interpretive practice.” In Denzin, N.K. and Lincoln, Y.S. (Eds.), SAGE Handbook of Qualitative Research, Sage, Thousand Oaks, CA, pp. 487-508. 
This document is the author's version of an accepted manuscript of a published work that appeared in final form in Quality in Ageing and Older Adults, copyright (c) Emerald Publishing after peer review and technical editing by the publisher. To access the final edited and published work see [https://doi.org/10.1108/QAOA-04-2018-0016].

Koehn, S. (2009), “Negotiating candidacy: ethnic minority seniors' access to care”, Ageing and Society, Vol. 29 No. 4, pp. 585-608.

Health Council of Canada (2013). Canada's most vulnerable: improving health care for First Nations, Inuit and Métis seniors. Available at: http://publications.gc.ca/site/archiveearchived.html?url=http://publications.gc.ca/collections/collection_2013/ccs-hcc/H174-402013-eng.pdf(Accessed April 19 2018).

Manderson, B., McMurray, J., Piraino, E. and Stolee, P. (2012), “Navigation roles support chronically ill older adults through healthcare transitions: a systematic review of the literature", Health and Social Care in the Community, Vol. 20 No. 2, pp.113-27.

Martinez-Donate, A.P., Halverson, J., Simon, N.J., Schaaf Strickland, J., Trentham-Dietz, A., Smith, P.D., et al. (2013), "Identifying health literacy and health system navigation needs among rural cancer patients: findings from the Rural Oncology Literacy Enhancement Study”, Journal of Cancer Education, Vol. 28 No. 3, pp. 573-81.

Powers, P. (1996), "Discourse analysis as a methodology for nursing inquiry", Nursing Inquiry, Vol. 3, pp. 207-17.

Robinson-White, S., Conroy, B., Slavish, K. and Rosenzweigh, M. (2010), "Patient navigation in breast cancer: a systematic review”, Cancer Nursing, Vol. 33 No. 2, pp.127-40.

Rootman, I. and Gordon-El-Bihbety, D. (2008), A Vision for a Health Literate Canada: Report of the expert panel on health literacy. Canadian Public Health Association, Ottawa, ON. Retrieved from: https://www.cpha.ca/sites/default/files/uploads/resources/healthlit/report_e.pdf 
This document is the author's version of an accepted manuscript of a published work that appeared in final form in Quality in Ageing and Older Adults, copyright (c) Emerald Publishing after peer review and technical editing by the publisher. To access the final edited and published work see [https://doi.org/10.1108/QAOA-04-2018-0016].

Segall A. and Chappell, N. (2000), Health and Health Care in Canada, Prentice Hall, Toronto, ON.

Smith, J.L. (2007), “Critical discourse analysis for nursing research”, Nursing Inquiry, Vol. 14, pp. 60-70.

Taylor, M.G. and Quesnel-Vallée, A. (2017), “The structural burden of caregiving: shared challenges in the United States and Canada", Gerontologist, Vol. 57 No.1, pp. 19-25.

Tracy, S.J. (2010), “Qualitative quality: eight "big tent” criteria for excellent qualitative research", Qualitative Inquiry, Vol. 16 No. 10, pp. 837-51.

Williams, A. P., Deber, R., Baranek, P. and Gildiner, A. (2001), "From medicare to home care: Globalization, state retrenchment, and the profitization of Canada's health-care system”, In Armstrong, P., Armstrong, H., and Coburn, D. (Eds.), Unhealthy times: Political economy perspectives on health and care, Oxford University Press, Don Mills, ON, pp. 7-30.

Woolford, A. and Curran, A. (2012), “Community positions, neoliberal dispositions: managing non-profit social services within the bureaucratic fields", Critical Sociology, Vol. 39 No. 1, pp. $45-63$. 